\title{
BEHAVIOUR OF CFST MEMBERS UNDER COMPRESSION EXTERNALLY REINFORCED BY CFRP COMPOSITES
}

\author{
M. C. Sundarraja ${ }^{1}$, G. Ganesh Prabhu \\ Thiagarajar College of Engineering, Madurai, Tamilnadu, India \\ E-mail: ${ }^{1}$ mcsciv@tce.edu (corresponding author) \\ Received 01 Jun. 2011; accepted 08 Jul. 2011
}

\begin{abstract}
This research is aimed at investigating the structural improvements of concrete filled steel tubular (CFST) sections with normal strength concrete externally bonded with fibre reinforced polymer (FRP) composites. For this study, compact mild steel tubes were used with the main variable being FRP characteristics. Carbon fibre reinforced polymer (CFRP) fabrics was used as horizontal strips (lateral ties) with several other parameters such as the number of layers and spacing of strips. Among twenty one columns, eighteen were externally bonded by CFRP strips having a constant width of $50 \mathrm{~mm}$ with a spacing of $20 \mathrm{~mm}$ and $40 \mathrm{~mm}$ and the remaining three columns were unbounded. Experiments were undertaken until column failure to fully understand the influence of FRP characteristics on the compressive behaviour of square CFST sections including their failure modes, axial stressstrain behaviour, and enhancement in load carrying capapcity. It was found that the external bonding of CFRP strips provides external confinement pressure effectively and intended to delay the local buckling of steel tube and also to improve the load carrying capacity further.
\end{abstract}

Keywords: CFST members, CFRP fabrics, strengthening, compression, externally bonded.

Reference to this paper should be made as follows: Sundarraja, M. C.; Ganesh Prabhu, G. 2013. Behaviour of CFST members under compression externally reinforced by CFRP composites, Journal of Civil Engineering and Management 19(2): 184-195.

\section{Introduction}

Composite construction may be considered as a reliable choice of attaining proper balance between the advantages it offers and the cost. An extensive variety of composite columns are available nowadays, but the concrete filled steel tubular (CFST) sections are most commonly used. CFST members are used in diversity of applications due to their excellent earthquake resistant properties such as high ductility, large energy absorption capacity and high-strength capacity. Steel tube lies in the outer limits can serve as formwork for the concrete infill during construction in addition local inward buckling commonly observed in bare steel tube columns is effectively prevented. In the meanwhile, aging of infrastructures concerned with the metallic structures and member deterioration of steel structures due to corrosion are often reported. Various strengthening or rehabilitation techniques such as section enlargement, external bonding of steel plates and fibers, etc. has been proposed to overcome these problems. In the past, section enlargement method has been proved as a suitable method for the rehabilitation of reinforced concrete columns. It was also expected that this method will be effective in repairing of CFST columns. However, it resulted in a significant increase in the column cross-section and the construction time is too long. Compared to the above methods, plate bonding technique provides a practical and cost effective solution. The earliest investigators utilized steel plates for external strengthening. Though the technique was successful in practice, it posed some harms such as adding self-weight, required heavy lifting equipment to place the plates in position, difficulty in shaping and fitting in complex profiles and complication in bonding/welding and furthermore added plates are susceptible to corrosion which leads to an increase in future maintenance costs. In contrast, rehabilitation using fibre reinforced polymer (FRP) composites do not exhibit any of these drawbacks.

Though the composite materials were introduced in the year 1909, the composite industry began to bloom only after 1930s (Balazs, Borosnyoi 2001). Glass fibre reinforced polymers (GFRP) were first used in aircraft radar covers at the end of 1930s (Hollaway 1993) and FRP boat hulls and car bodies were developed with glass fibres as the major reinforcement (Lam, Teng 2002). As a non-conductive material, glass was used as an insulator to prevent galvanic corrosion of metals. However, under certain conditions of exposure, glass fibres proved to be sensitive to alkaline 
environments and moisture attack (Peters 1998). At the end of 1960s, Royal Aircraft Establishment had developed the carbon fibre reinforced polymer for special applications (Hollaway 1993). Unlike glass, carbon is an electrical conductor and hence galvanic corrosion could take place if carbon fibres are placed in direct contact with metals (Miller et al. 2001) but such fibres behave very well against creep deformation and relaxation (Balazs, Borosnyoi 2001). After introduction of advanced composite materials in the construction industry, the second generation utilized those materials in external strengthening technique. The application of carbon fibre reinforced polymer (CFRP) with reinforced concrete structures has been widely carried out and reported in the past few decades. However, research related to FRP applications to steel structures has started quite recently and there are few applications still in practice due to uncertainties concerning the long term behaviour of these applications and the bonding between the composite materials and steel (Hollaway 1994).

One of the first known studies on this topic involved, the use of CFRP laminates to repair steel structures conducted by Sen and Liby (1994). Six composite beams were tested under four-point loading. An epoxy adhesive was used to bond the CFRP laminates to the tension flange of the steel beam in different configurations. High strength steel bolts were also used in an attempt to transfer the load to CFRP laminates. The results indicated that even though significant ultimate strength was gained but more modest improvement in the elastic response are required. In another investigation, Jiao and Zhao (2004) studied the performance of butt-welded very high strength (VHS) steel tubes strengthened with CFRP under axial tension. Three types of epoxy resins with different lap shear strength were used. Three kinds of failure modes such as adhesive failure, fiber tear and mixed failure were observed. The above investigation concluded that a significant strength can be achieved using CFRP-epoxy strengthening technique and also they recommended suitable epoxy adhesive for strengthening of VHS steel tubes.

Photiou et al. (2006) investigated the effectiveness of an ultra-high modulus, and high modulus CFRP prepreg in strengthening the artificially degraded steel beam of rectangular cross-section under four-point loading by using two different wrapping configurations. The beam containing the ultra-high modulus CFRP was failed when the ultimate strain of the carbon fibre was reached in the pure moment region. The failure load exceeded the plastic collapse load of the undamaged beam. The beams strengthened by using the high modulus CFRP exhibited ductile response leading to very high deflections even after higher ultimate load was reached and also neither fibre breakage nor adhesive failure was observed.
Seica and Packer (2007) investigated the FRP materials for the rehabilitation of tubular steel structures for underwater applications. Six tubes were wrapped with CFRP composites. In that two specimens were prepared under in-air conditions and remaining four were prepared under seawater curing conditions. Specimens were tested under four point loading. It was observed that the ultimate strength of the tubes wrapped under in-air and seawater curing conditions having $16-27 \%$ and $8-21 \%$ more than that of bare steel beam respectively. Tao and Han (2007) presented the results of axial compression and bending tests of firedamaged concrete-filled steel tubes repaired using unidirectional CFRP composites. Both circular and square specimens were tested to investigate the repair effects of CFRP composites on them. The test results showed that the load-carrying capacity and the longitudinal stiffness of CFRP-repaired CFST stub columns increased while their ductility decreased with the increasing number of CFRP layers. In another study, Tao et al. (2006) repaired the fire-exposed CFST beams and columns by unidirectional CFRP composites. The test results showed that the load-bearing capacity was enhanced by the fibre jackets to some extent, while the influence of CFRP repair on stiffness was not apparent. Choi and Xiao (2010) presented a simplified analytical model of the CFST member confined by CFRP jackets with different parameters in order to strengthen the traditional CFST column system. The accuracy of the analytical model results was compared to the experimental results conducted by the traditional method.

From the past research, it can be observed that there have been investigations done with the use of CFRP as a strengthening material for metallic members and also presence of CFRP significantly enhance the behavior of steel tubular members. However, research related to strengthening of CFST members using fibre are not widespread and also more tests are required to derive an optimal combination of fibre orientation, number of layers and sequence in applying CFRP layers. The main focus of the study is to experimentally investigate the suitability of carbon fibre reinforced polymer for strengthening of CFST column members and also compare the effectiveness of geometric shapes of the upgrading material (i.e. wrapping scheme). Finally, suitable wrapping scheme that can be used to repair CFST members was recommended. Furthermore, to eliminate the galvanic corrosion between steel tube and CFRP, a thin layer of glass fibre mat was introduced between steel and CFRP.

\section{Materials}

\subsection{Concrete}

The concrete mix proportion designed by IS method to achieve the strength of $30 \mathrm{~N} / \mathrm{mm}^{2}$ and was 1:1.39:2.77 by weight. The designed water cement 
Table 1. Details of concrete mixes

\begin{tabular}{lcc}
\hline $\begin{array}{l}\text { Dimension of } \\
\text { concrete cube }\end{array}$ & $\begin{array}{c}\text { Average } \\
\text { ultimate load } \\
(\mathrm{kN})\end{array}$ & $\begin{array}{c}\text { Average cube } \\
\text { strength at } 28 \text { days } \\
\left(\mathrm{N} / \mathrm{mm}^{2}\right)\end{array}$ \\
\hline $150 \times 150 \times 150 \mathrm{~mm}$ & 871.66 & 38.75 \\
\hline
\end{tabular}

ratio was 0.35 . Three cube specimens of size $150 \times$ $150 \times 150 \mathrm{~mm}$ were cast and tested at the age of 28 days to determine the compressive strength of concrete. The test result of concrete is given in Table 1.

\subsection{Carbon fibre}

The unidirectional carbon fibre called MBrace 240, fabricated by BASF India Inc. was used in this study. It is a low modulus CFRP fibre having modulus of elasticity of $240 \mathrm{kN} / \mathrm{mm}^{2}$ and the tensile strength was $3800 \mathrm{~N} / \mathrm{mm}^{2}$. The thickness and width of the fibre was $0.234 \mathrm{~mm}$ and $600 \mathrm{~mm}$, respectively. It is fabric type and can be tailored into any desired shape. The properties of CFRP supplied by the manufacturer are given in Table 2.

\subsection{Adhesive}

The MBrace saturant supplied by BASF India Inc. was used in this study to get sufficient bonding between steel tube and carbon fibre. It is a two part systems, a resin and a hardener and the mixing ratio was 100:40 (B:H). The properties of saturant supplied by the manufacturer are summarized in Table 3.

\subsection{Steel tube}

The square hollow steel tube confirming to IS 4923 : 1997 and IS 10262: 1987 having a dimension of $91.5 \times 91.5 \mathrm{~mm}$ was used in this study. The thickness and height of the square hollow steel tube were 3.6 $\mathrm{mm}$ and $600 \mathrm{~mm}$, respectively. The yield strength provided by the manufacturer was $250 \mathrm{~N} / \mathrm{mm}^{2}$.

Table 2. Properties of carbon fiber

\begin{tabular}{lll}
\hline S. No & \multicolumn{1}{c}{ Properties } & \multicolumn{1}{c}{ Value } \\
\hline 1 & Modulus of elasticity & $240 \mathrm{kN} / \mathrm{mm}^{2}$ \\
2 & Tensile strength & $3800 \mathrm{~N} / \mathrm{mm}^{2}$ \\
3 & Density & $1.7 \mathrm{~g} / \mathrm{cm}^{2}$ \\
4 & Thickness & $0.234 \mathrm{~mm}$ \\
\hline
\end{tabular}

Table 3. Properties of saturant

\begin{tabular}{llc}
\hline S. No & \multicolumn{1}{c}{ Properties } & \multicolumn{1}{c}{ Value } \\
\hline 1 & Mixed density (kg/litre) & $1.13 \pm 0.03$ \\
2 & Mixing ratio (B:H) & $100: 40$ \\
3 & Mixed viscosity at $25^{\circ} \mathrm{C}$ & $4000 \pm 500$ \\
4 & Setting time & $<3$ hours at $25^{\circ} \mathrm{C}$ \\
\hline
\end{tabular}

\section{Experimental study}

\subsection{Specimen fabrication}

The $600 \mathrm{~mm}$ height square hollow tubes were cut from $6 \mathrm{~m}$ length hollow tubes. To get the flat surface, both ends of the steel tube were surfaced by the surface grinding machine. Inside portion of the hollow steel tubes were thoroughly wire brushed to remove the rust and loose debris presented. Then the hollow steel tube specimens were filled with concrete and compacted by a steel rod to avoid any flaws or air gaps that occur inside the specimen. To eliminate the leakage of slurry during compaction, a steel plate was placed at the bottom prior to filling concrete. The concrete was cured for 28 days. Surface preparation of the metal substrate is very important to achieve good bonding between steel tube and CFRP fabrics. The strength of the adhesive bond is directly proportional to the quality of the surfaces to which it is bonded. So the exposed surface of the tubular specimen was blasted by the coarse sand to remove the rust and also to make the surface rough one. The entire sand blasted surface was cleaned by using acetone to remove all contaminant materials before retrofitted with the fibres. Prior to the columns strengthened by carbon fibre, the glass fibre fabric was introduced between the steel surface and CFRP composites to eliminate the galvanic corrosion. Finally, the carbon fibres were bonded to the exterior surface of the CFST members with the different wrapping schemes and thicknesses. During wrapping of fibre fabrics, the resin and hardener are correctly proportioned and thoroughly mixed together and the excess epoxy and air were removed using a ribbed roller moving in the direction of the fibre.

\subsection{Description of specimens}

Among twenty one specimens, eighteen were externally bonded by CFRP strips having a constant width of $50 \mathrm{~mm}$ wrapped with the spacing of $20 \mathrm{~mm}$ and $40 \mathrm{~mm}$ and remaining three specimens were unbonded. The wrapping schemes are shown in Fig. 1. The size and length of the columns used were $91.5 \times 91.5 \times 3.6 \mathrm{~mm}$ and $600 \mathrm{~mm}$, respectively. To identify the specimen easily, the columns were designated with the names such as HS-50-20-T1, HS-50-20-T2, HS-50-20-T3, HS-50-40-T1, HS-50-40-T2 and HS-50-40-T3. For example, the specimen HS-50-20-T3 specifies that it was strengthened by three (3) layers of $50 \mathrm{~mm}$ width horizontal strip (HS) of CFRP fabrics in transverse direction (T) with the spacing of $20 \mathrm{~mm}$. The control columns are specified as $\mathrm{CC} 1, \mathrm{CC} 1$ and $\mathrm{CC} 3$.

\subsection{Experimental setup}

The CFST columns were tested in compression testing machine of capacity $2000 \mathrm{kN}$. Each member was 


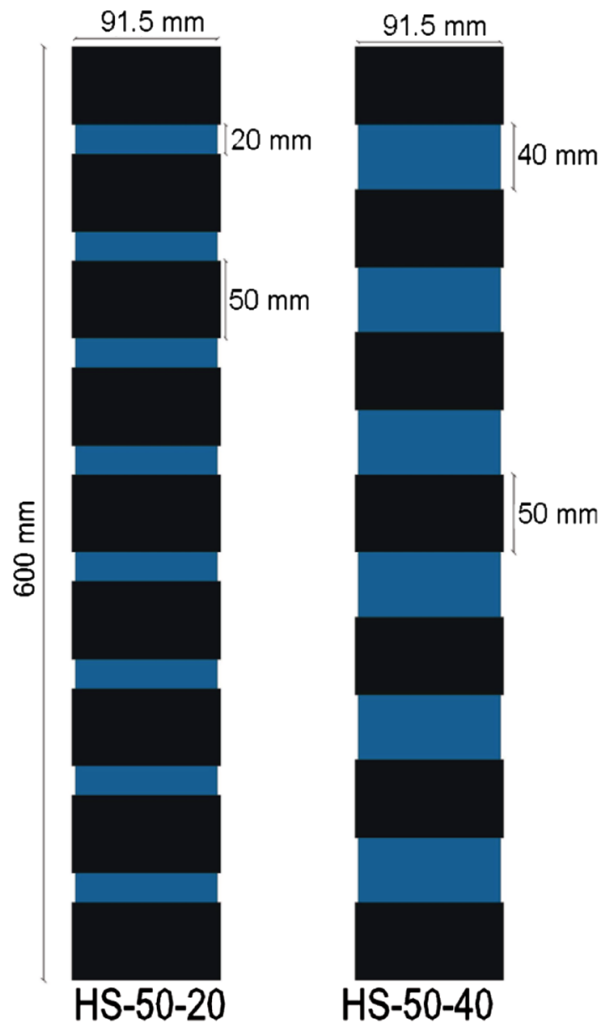

Fig. 1. Wrapping scheme

positioned on the supports taking care to ensure that its centerline was exactly in line with the axis of the machine. The verticality of the specimens was checked using plumb bob and sprit level. The specimens were instrumented to measure longitudinal axial compression. The load was applied to the column by hydraulic jack and monitored by using $1000 \mathrm{kN}$ capacity load cell. Axial deformation of the column was measured by using linear voltage displacement transducer (LVDT) which was kept at top of the jack. The load cell and LVDT were connected with the 16-Channel Data Acquisition System to store the respective data. At the beginning, a small load of $20 \mathrm{kN}$ was applied slowly, so that the columns settle properly on its supports. Then the load was removed after checking the proper functioning of the instrumentation. The trial load was applied again slowly and the column was then tested to failure by applying the compressive load in small increments and the observations such as axial deformation and ultimate load were carefully recorded. The load at which the CFRP starts rupturing and the nature of failure were also noted for each column. The experimental setup is shown in the Fig. 2.

\section{Results and discussion}

\subsection{Failure modes}

The columns were loaded to until failure to understand the influence of carbon fibre fabrics on the axial

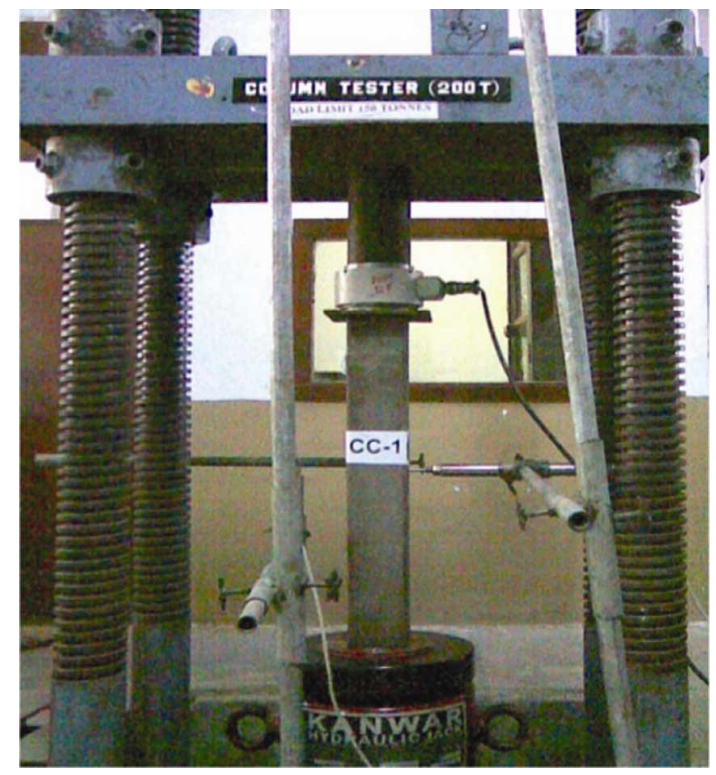

Fig. 2. Experimental setup

behavior of CFST members. Until reach a load of $850 \mathrm{kN}$ on jack, a linear response was observed in all unwrapped specimens and thereafter non-linear response was observed. Outward buckling at the top on all four sides of the steel tube was occurred in the case of control specimens $\mathrm{CC} 1, \mathrm{CC} 2$ and $\mathrm{CC} 3$ at the load of $934 \mathrm{kN}, 928 \mathrm{kN}$ and $923 \mathrm{kN}$, respectively, which is shown in Fig. 3. Crushing of concrete was not occurred in order that the applied load was decreased slowly after the failure load but favourable enhancement in ductility performance was noticed.

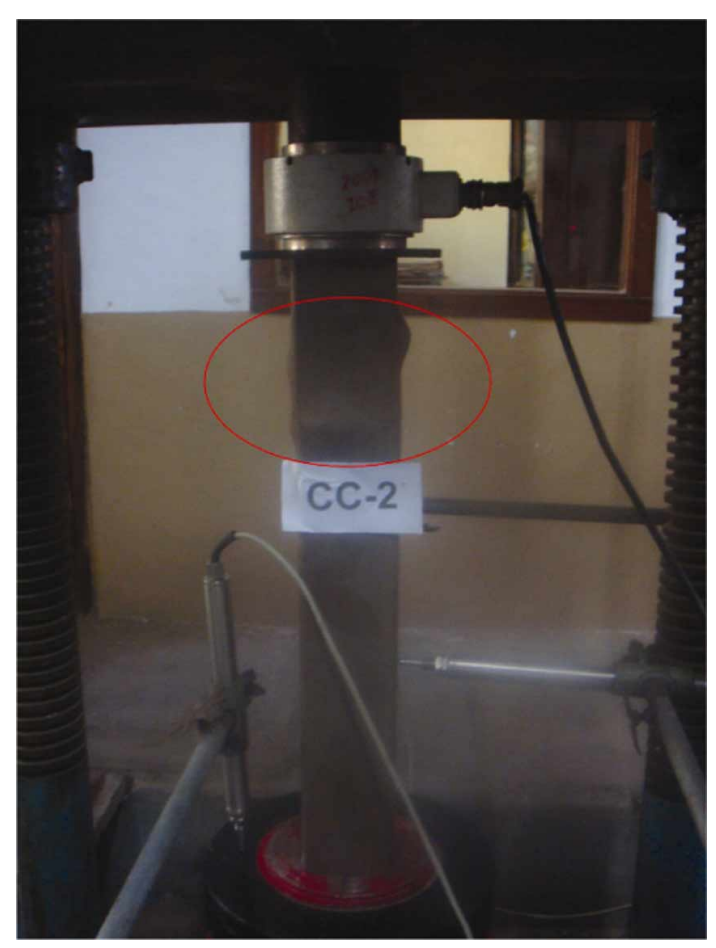

Fig. 3. Failure mode of column CC2 
Failure of specimens HS-50-20-T1(1), HS-50-20T1(2) and HS-50-20-T1(3) were occurred at the load of $969 \mathrm{kN}, 983 \mathrm{kN}$ and $989 \mathrm{kN}$, respectively and at the same time the axial deformation of the specimens exceeded their permissible limit. The rupture of fibre was occurred at top edge of the columns and thereafter delamination of fibre due to outward buckling of steel tube was observed on the sides of the CFST members is shown in Fig. 4. Therefore, it can be understood that a good composite action exist between the two components were confirmed. After rupture of CFRP, the load gets suddenly reduced. The abrupt reduction in load may be attributed to immediate absence of confinement provided by the CFRP and resulted outward buckling of tubes. The similar failure mode was observed in the case of specimens strengthened with two layers of CFRP fabrics [HS-50-20T2(1), HS-50-20-T2(2) and HS-50-20-T2(3)] and the rupture of fibre was occurred at $250 \mathrm{~mm}$ below the top of the column as shown in Fig. 5. At the initial stage, crushing sound of resin was observed in the case of columns HS-50-20-T3(1), HS-50-20-T3(2) and HS-50-20-T3(3). After further loading, until reaching a load of $1000 \mathrm{kN}$ on jack, all three columns were exhibited linear elastic behavior and thereafter nonlinear response was observed. At the respective failure load of control column ( $\mathrm{CC} 1)$, no obvious changes in the specimens were noticed and observed an axial deformation of $6.9 \mathrm{~mm}$.

Among these, the specimens HS-50-20-T3(1) and HS-50-20-T3(2) exhibited a sudden failure which result in rupture of CFRP jackets occurred at the

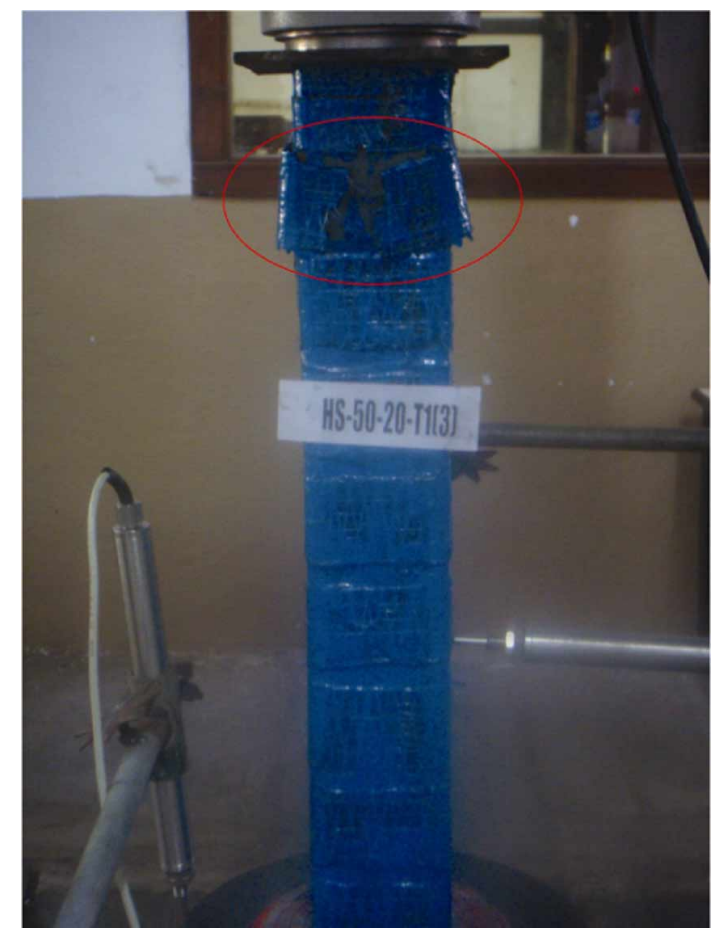

Fig. 4. Failure mode of column HS-50-20-T1(3)

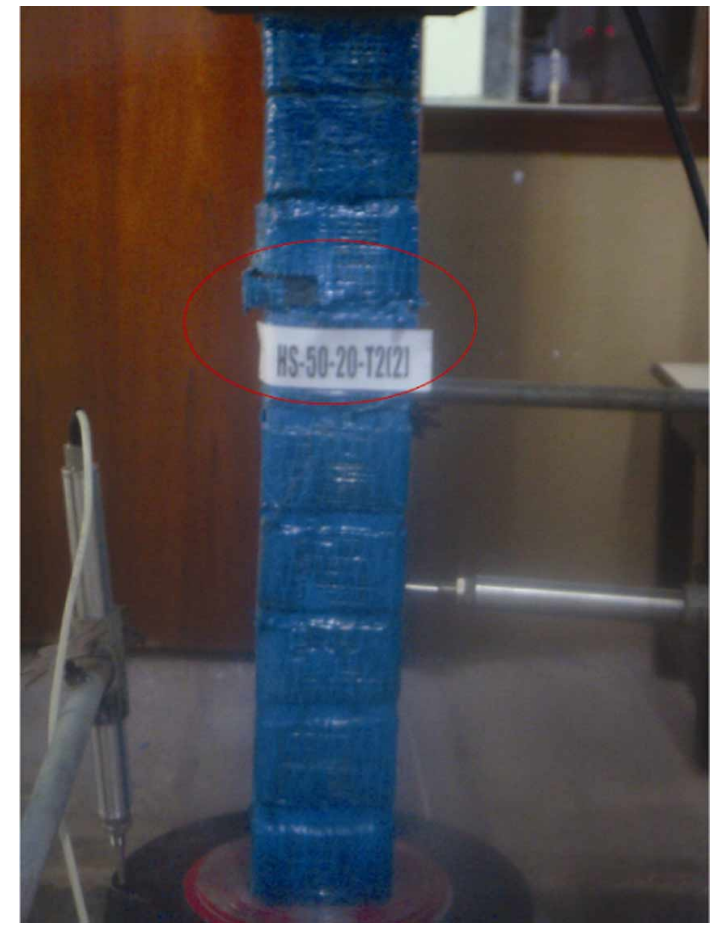

Fig. 5. Failure mode of column HS-50-20-T2(2)

bottom of specimen after they attained their peak loads and is shown in Fig. 6. And the specimen HS-20-T3(3) failed by rupture of fibre and it was observed at mid height of the specimen at the load of $1165 \mathrm{~N}$.

The specimens HS-50-40-T1(1) and HS-50-40T1(2) failed by local buckling of steel tube observed in unbonded region at the mid height and at $50 \mathrm{~mm}$

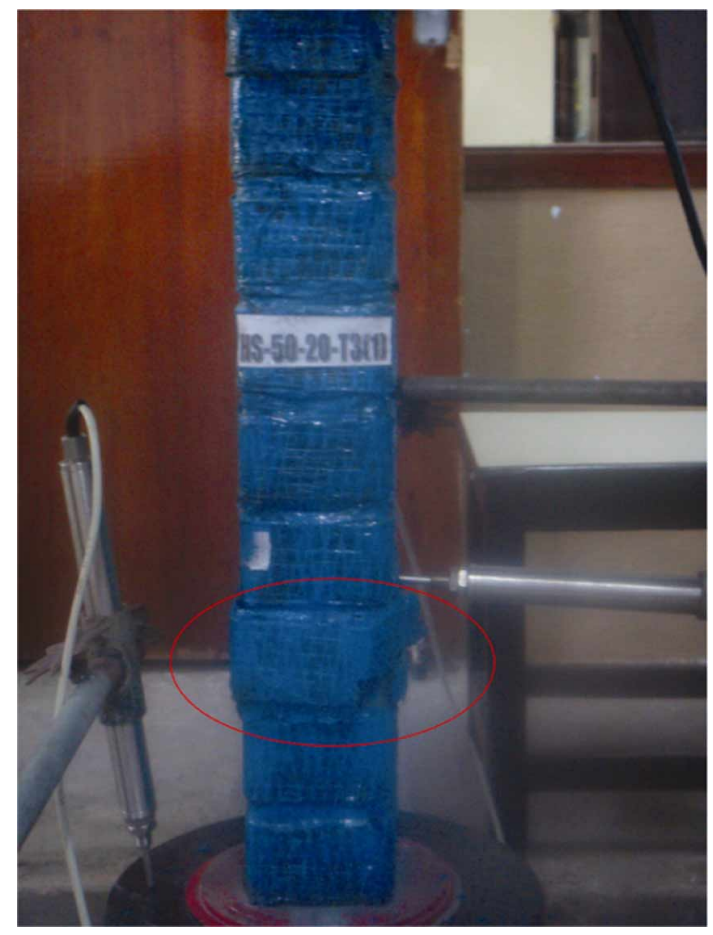

Fig. 6. Failure mode of column HS-50-20-T3(1) 
from the bottom of the column respectively, and at the load of $956 \mathrm{kN}$ and $972 \mathrm{kN}$, respectively. In addition no rupture of fibre was identified which is shown in Fig. 7. But the column HS-50-40-T1(3) failed by local buckling of steel tube followed by rupture of fibre occurred at the top of the column and at the load of $989 \mathrm{kN}$ and furthermore rupture of fibre was observed only at face of the column. From the above observations, it can be noted that when increasing the spacing of CFRP strips, the unwrapped area will become more and subjected to maximum strain during loading and the buckling of steel tube was occurred in the unwrapped zone due to insufficient confining pressure provided by the FRP composites. The similar behaviour was occurred in the case of specimens HS-50-40T2(1), HS-50-40-T2(2) and HS-50-40-T2(3) but the load carrying capacity was higher. Among these, the columns HS-50-40-T2(1) and HS-50-40-T2(3) failed by local buckling of steel tube which was observed at 140 $\mathrm{mm}$ from the bottom of the column and it was observed at mid height in the case of column HS-50-40-T2(2) which are shown in Figs 8 and 9.

Until reach a failure load of control column (CC1), there was no obvious change was observed in the columns HS-50-40-T3(1), HS-50-40-T3(2) and HS-50-40-T3(3) and also their axial deformation was $8.87 \mathrm{~mm}, 6.2 \mathrm{~mm}$ and $6.72 \mathrm{~mm}$, respectively. After further loading, initial rupture of fibre was observed at the load of $962 \mathrm{kN}, 976 \mathrm{kN}$ and $933 \mathrm{kN}$, respectively. Among the three columns, HS-50-40-T3(1) and HS-50-40-T3(3) exhibited local buckling of steel tube without any rupture of fibre and was occurred at

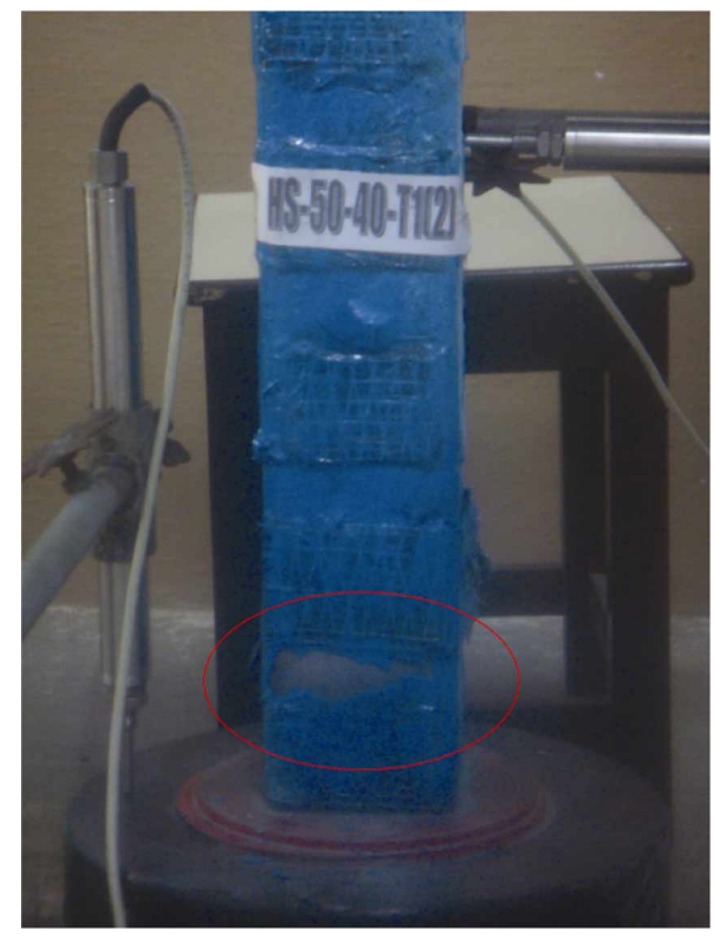

Fig. 7. Failure mode of column HS-50-40-T1(2)

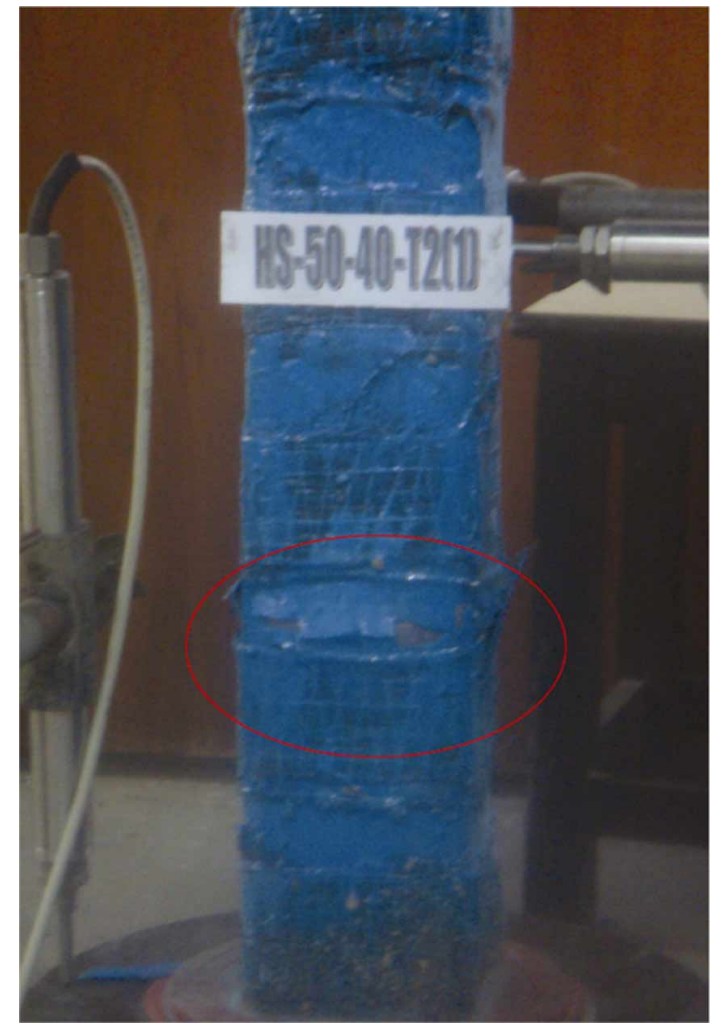

Fig. 8. Failure mode of column HS-50-40-T2(1)

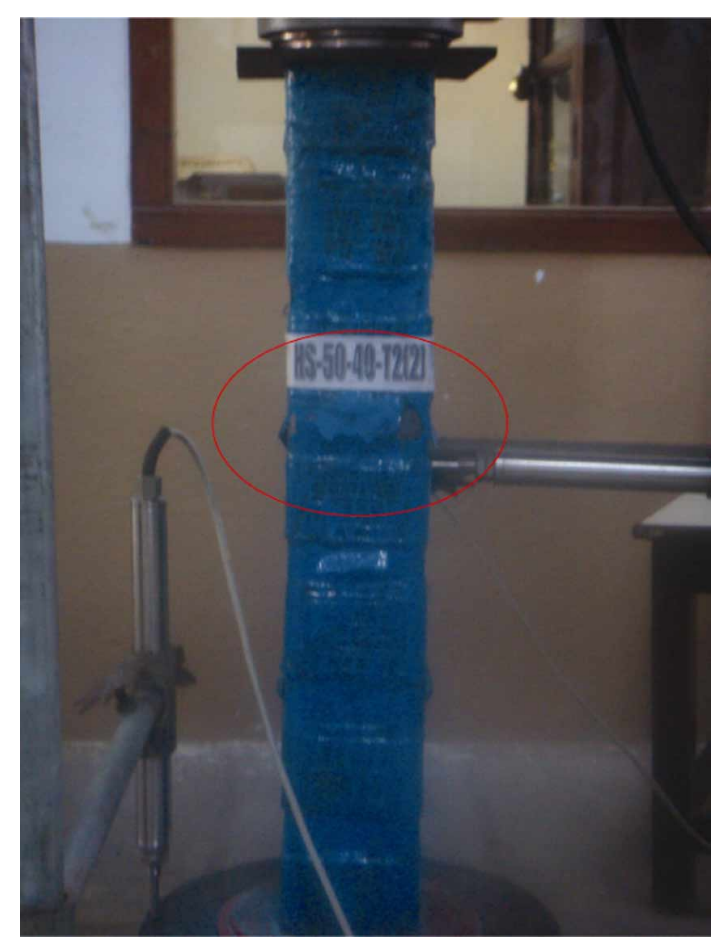

Fig. 9. Failure mode of column HS-50-40-T2(2)

$1033 \mathrm{kN}$ and $1032 \mathrm{kN}$, respectively as shown in Fig. 10. The column HS-50-40-T3(2) failed by rupture of fibre occurred at top edge of the columns due to outward buckling of steel tube at the load of $1022 \mathrm{kN}$. In the overview, when increasing the number 


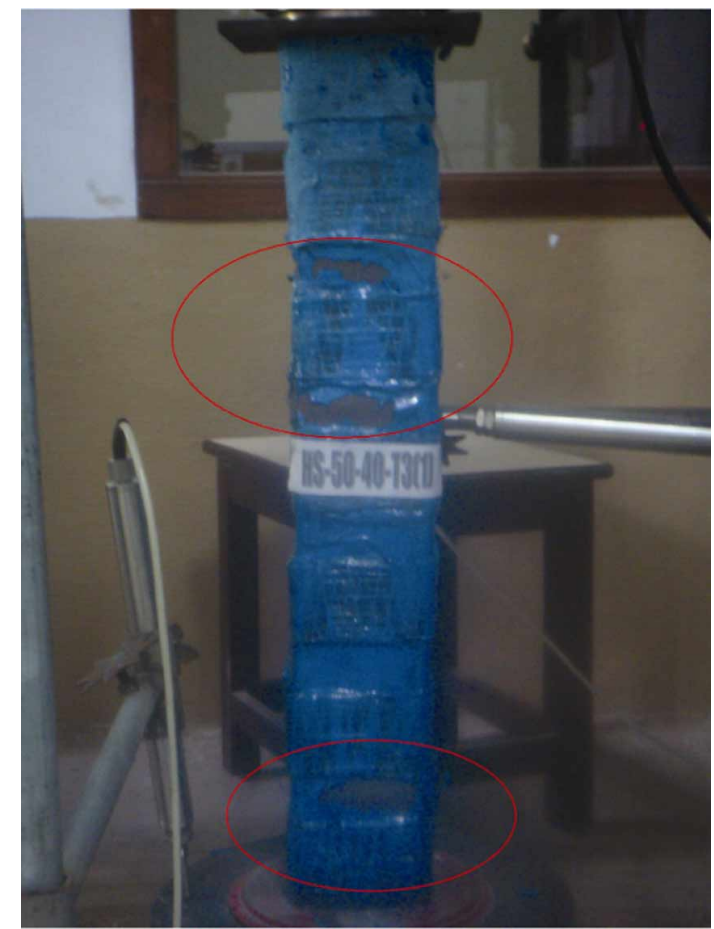

Fig. 10. Failure mode of column HS-50-40-T3(1)

of layers, there may be possible failure of local buckling of steel tube alone rather than fibre rupture.

\subsection{Axial stress-strain behavior}

Test results of the columns such as maximum axial deformation and percentage of control in axial deformation with respect to reference column are summarized in Table 4.

The axial stress strain behavior of CFST members confined by CFRP fabrics with respect to control specimen is shown in Figs 11 to 13. From that it was observed that the control and confined columns exhibited the elastic behavior at initial stage followed by in-elastic response when increasing the load further and in addition significant fall in curve was observed at the peak stage due to sudden rupture of CFRP. The CFST members confined by CFRP fabrics sustained higher ultimate load and larger axial deformation compared to control column. And also, it was noticed that columns confined with three layers of CFRP have more ability to control the axial deformation compared to columns confined by one and two layers of CFRP. Comparing the behavior of columns HS-50-20-T1(2), HS-50-20T2(2) and HS-50-20-T3(1) to that of control column (CC1), all three columns showed significant control in axial deformation and enhancement in stiffness, especially, the behavior of HS-50-20-T3(1) was outperformed and is shown in Fig. 14. Until reach failure load of CC1, the columns HS-50-20-T1(2), HS-50-20-T2(2) and HS-50-20-T3(1) displayed linear elastic behaviour and thereafter nonlinear elastic behaviour was observed as shown in Fig. 11. At the corresponding failure load of $\mathrm{CC} 1$, mid span deflection of specimens HS-50-20-T1(2), HS-50-20-T2(2) and HS-50-20-T3(1) observed was lesser than that of $\mathrm{CC} 1$.

Table 4. Failure load and Load carrying capacity of all specimens

\begin{tabular}{|c|c|c|c|c|c|}
\hline $\begin{array}{l}\text { Designation of } \\
\text { columns }\end{array}$ & $\begin{array}{c}\text { Failure } \\
\text { load }(\mathrm{kN})\end{array}$ & $\begin{array}{l}\text { Load at initial } \\
\text { rupture of FRP } \\
\qquad(\mathrm{kN})\end{array}$ & $\begin{array}{c}\text { Maximum axial } \\
\text { deformation }(\mathrm{mm})\end{array}$ & $\begin{array}{l}\% \text { of reduction in axial } \\
\text { deformation compared to } \\
\text { CC1 }(\mathrm{kN})\end{array}$ & $\begin{array}{l}\% \text { of increase in axial } \\
\text { load carrying capacity } \\
(\mathrm{kN})\end{array}$ \\
\hline $\mathrm{CC} 1$ & 934 & - & 11.98 & - & - \\
\hline $\mathrm{CC} 2$ & 928 & - & 12.28 & - & - \\
\hline $\mathrm{CC} 3$ & 923 & - & 11.99 & - & - \\
\hline HS-50-20-T1(1) & 969 & 831 & 8.66 & 14.58 & 3.75 \\
\hline HS-50-20-T1(2) & 983 & 826 & 7.95 & 12.12 & 5.25 \\
\hline HS-50-20-T1(3) & 1008 & 843 & 8.33 & 16.72 & 7.92 \\
\hline HS-50-20-T2(1) & 1072 & 923 & 10.96 & 56.65 & 14.78 \\
\hline HS-50-20-T2(2) & 1052 & 915 & 10.09 & 62.32 & 12.63 \\
\hline HS-50-20-T2(3) & 1043 & 921 & 11.27 & 60.15 & 11.67 \\
\hline HS-50-20-T3(1) & 1125 & 943 & 13.17 & 92.05 & 20.45 \\
\hline HS-50-20-T3(2) & 1120 & 904 & 11.70 & 91.50 & 19.91 \\
\hline HS-50-20-T3(3) & 1185 & 932 & 10.29 & 91.12 & 26.87 \\
\hline HS-50-40-T1(1) & 956 & 836 & 9.73 & 5.88 & 5.05 \\
\hline HS-50-40-T1(2) & 972 & 834 & 9.76 & 7.21 & 6.81 \\
\hline HS-50-40-T1(3) & 989 & 846 & 9.98 & 6.21 & 8.68 \\
\hline HS-50-40-T2(1) & 1033 & 912 & 10.87 & 42.23 & 13.52 \\
\hline HS-50-40-T2(2) & 1032 & 927 & 11.12 & 31.22 & 13.41 \\
\hline HS-50-40-T2(3) & 1022 & 951 & 10.76 & 39.63 & 12.31 \\
\hline HS-50-40-T3(1) & 1084 & 962 & 11.18 & 50.15 & 19.12 \\
\hline HS-50-40-T3(2) & 1112 & 976 & 11.07 & 36.24 & 22.20 \\
\hline HS-50-40-T3(3) & 1099 & 933 & 11.23 & 49.23 & 20.77 \\
\hline
\end{tabular}




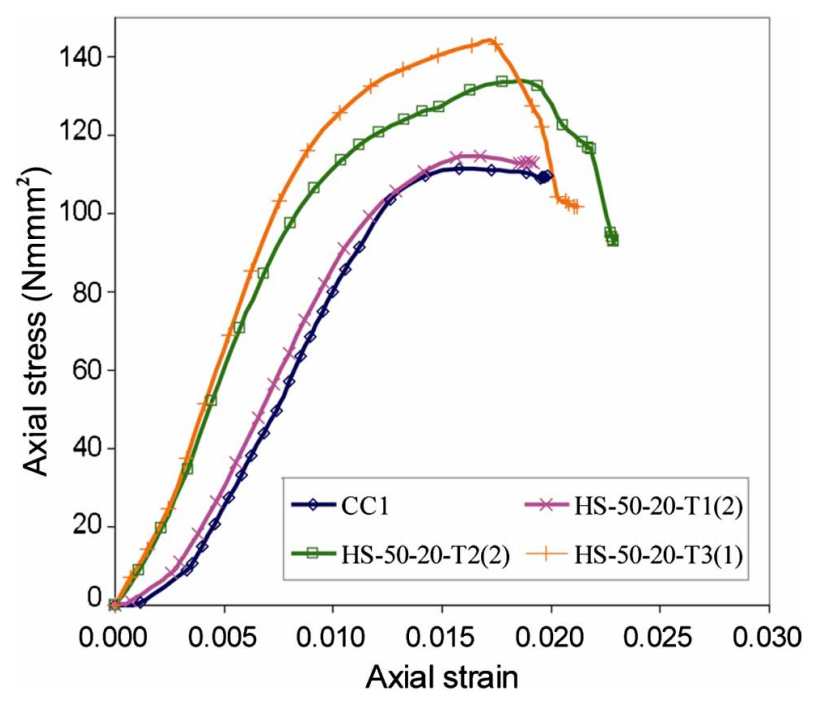

Fig. 11. Axial stress strain behaviour of columns HS-50-20 comparison

The enhancement in axial deformation and its control of above specimens was $12.2 \%, 56.66 \%$ and $89.05 \%$ more than that of control column, respectively. Comparing the behavior of HS-50-20-T2(2) to that of HS-50-20-T3(1), axial stress-strain behavior of column HS-50-20-T2(2) followed the same path of HS-50-20T3(3) until reach the load of $670 \mathrm{kN}$ as shown in Fig. 13 and at the same time the enhancement in axial deformation control of HS-50-20-T3(3) was much better than that of column HS-50-20-T2(3) which is shown in Fig. 14. From the Fig. 14, it can be seen that the columns confined with three layers of CFRP tend to have more ability to control axial deformation compared to those columns confined by one and two layers of CFRP, in addition, the enhancement in axial deformation control due to increase in number of layers was also not proportional. The above nonlinearity in axial deformation control when increasing the number of layers of fibre may be attributed to crushing of resin lying in between the fibres. When the resin started to crush, a sudden drop in substantial load transfer was occurred. As a result, non-linearity in axial deformation control was observed. Furthermore, by increasing the number of layers of fibre fabrics, the number of resin layers also increased so that more nonlinearity in axial deformation control was observed.

The FRP strips having a spacing of $40 \mathrm{~mm}$ effectively reduce the axial deformation and also increase the stiffness of the columns as shown in Fig. 12. Since sufficient amount of confining pressure was not generated by FRP fabrics in the case of column HS-5040-T1(3), axial deformation control of column was very small. And at the same time, due to more number FRP layers, the columns HS-50-40-T2(1) and HS-5040-T3(2) showed better control in axial deformation compared to columns CC1 and HS-50-40-T1(2). It was

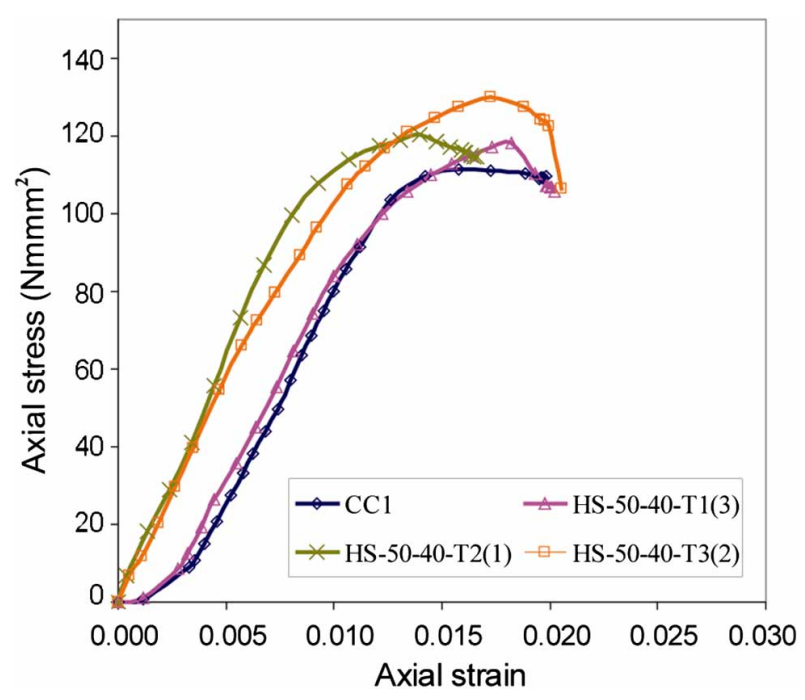

Fig. 12. Axial stress strain behaviour of columns HS-50-40 comparison

found that the specimens HS-50-40-T1(3), HS-5040-T2(1) and HS-50-40-T3(2) enhanced their axial deformation control by $6.2 \%, 42.23 \%$ and $36.24 \%$, respectively, compared to control specimen and their mid-span deflection at corresponding failure load of control column was $8.87 \mathrm{~mm}, 6.2 \mathrm{~mm}$ and $6.72 \mathrm{~mm}$, respectively, as shown in Fig. 15. Until reaching a failure load of $510 \mathrm{kN}$, column HS-50-40-T3(3) followed the same path of column HS-50-40-T2(3), and thereafter meager relaxation in deformation control was observed but better control in axial deformation was observed only after the load of $993 \mathrm{kN}$ onwards which is shown in Fig. 12. This meager relaxation in deformation control attributed to the failure of the resin at the interface between the steel tube substrate and the CFRP fabrics. The column HS-50-40-T2(1) has higher axial deformation of 8.75 compared to column HS-50-40-T3(2) which has a axial deformation of $7.64 \mathrm{~mm}$. The column HS-50-40-T3(2) enhanced their axial deformation control by $44.76 \%$ and $14.90 \%$ when compared to columns HS-50-40-T1(3) and HS50-40-T2(1), respectively, as shown in Fig. 15.

In the case of columns strengthened by CFRP strips having spacing of $20 \mathrm{~mm}$ and $40 \mathrm{~mm}$, the columns with three layers of fibre fabrics in both the wrapping schemes showed significant control in axial deformation, especially, the columns having $20 \mathrm{~mm}$ spacing of CFRP strips was outperformed which is shown in Figs 13 and 16. The enhancement in axial deformation control may be because of more confining pressure uniformly exerted by the CFRP strips.

Compared to column HS-50-40-T1(3), column HS-50-20-T1(2) followed the same path of HS-50-40T1(3) until failure but the load carrying capacity of column HS-50-20-T1(2) was high which is shown in Figs 13 and 16. The column HS-50-40-T1(3) has axial deformation of $9.92 \mathrm{~mm}$ little higher than that of 


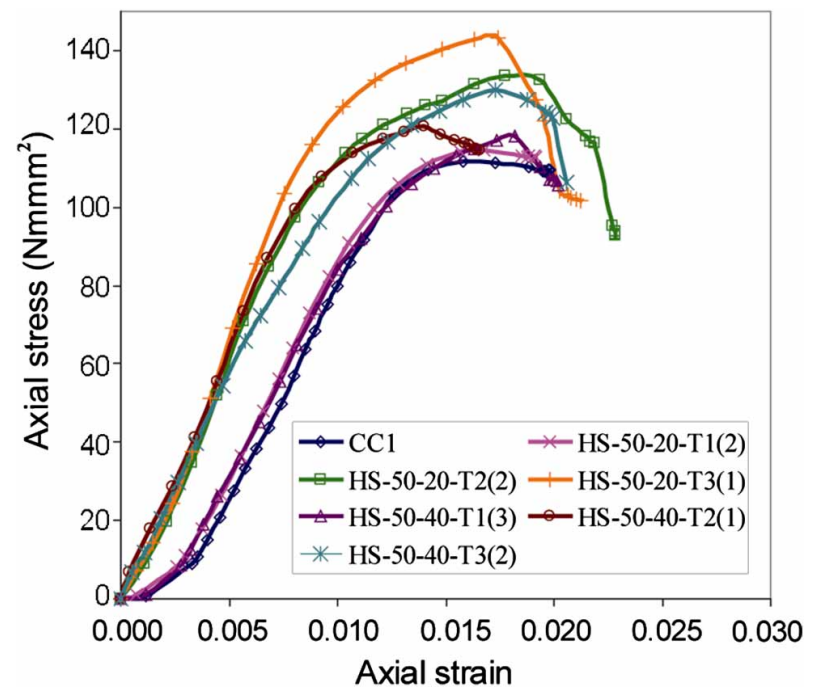

Fig. 13. Axial stress strain behaviour of all columns comparison

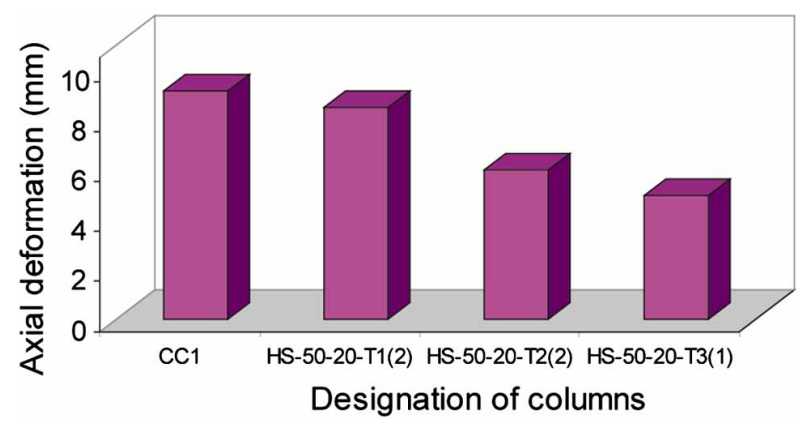

Fig. 14. Axial deformation of columns HS-50-20 comparison

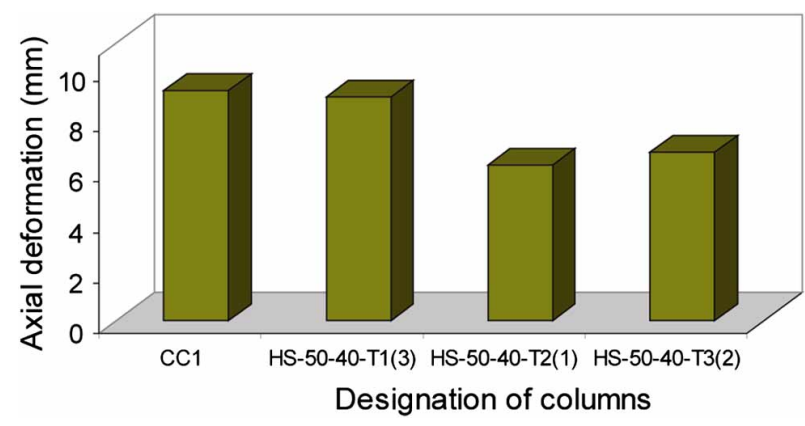

Fig. 15. Axial deformation of columns HS-50-40 comparison

column HS-50-20-T1(2) which has a axial deformation of $9.94 \mathrm{~mm}$ and is shown in Fig. 16. And also, the column HS-50-20-T2(2) tends to have more capability of controlling axial deformation compared to column HS-50-40-T2(1).

Fig. 16 also illustrates that the column HS-5040-T3(2) has more axial deformation $(10.8 \mathrm{~mm})$ than that of column HS-50-20-T3(1) $(9.32 \mathrm{~mm})$ and furthermore which is $15.87 \%$ more than that of HS-50-20T3(1). In overall, columns strengthened by $50 \mathrm{~mm}$

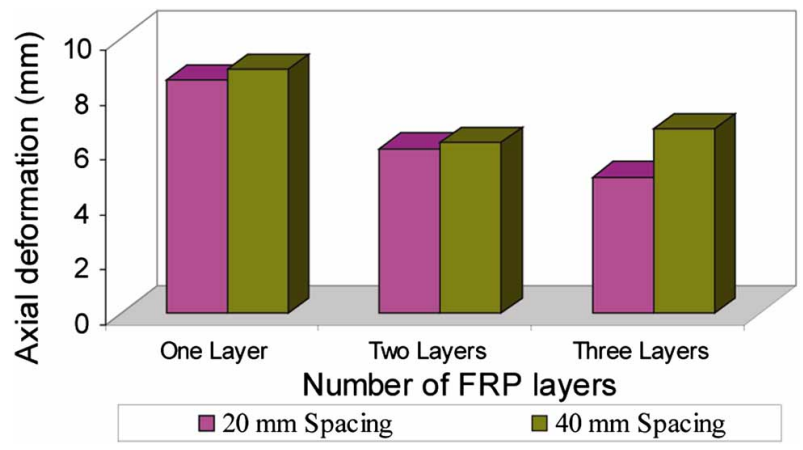

Fig. 16. Axial deformation with respect to number of CFRP layers - comparison

width CFRP strips having spacing of $20 \mathrm{~mm}$ effectively control the axial deformation compared to the column strengthened by same width of CFRP strips having a spacing of $40 \mathrm{~mm}$.

\subsection{Axial load carrying capacity}

Table 4 summarizes the maximum load carrying capacity and percentage increase in it of all CFRP strengthened columns compared with the control column. The experiments aimed at raising the axial strength of columns and also to advance the lateral confinement pressure by means of providing external CFRP strips in the form of horizontal lateral external ties. As expected, the external bonding of CFRP strips considerably enhance the load carrying capacity of the columns, especially the columns strengthened by three layers of CFRP strips in both the spacing were outperformed.

The enhancement in axial load carrying capacity of columns HS-50-20-T1(3), HS-50-20-T2(2) and HS-50-20-T3(1) was found to be $10.72 \%, 17.80 \%$, and $30.21 \%$ more than that of control column (CC1) respectively, and is shown in Fig. 17. In similar manner, the columns HS-50-40-T1(3), HS-50-40T2(1) and HS-50-40-T3(2) showed 8.68\%, 13.51\%, $22.19 \%$ more load carrying capacity than the control column respectively which is shown in Fig. 18. As a result, there is a good bonding action exist between the CFRP strips and steel tube and also external bonding of CFRP strips considerably provided the confining pressure to the column were proved. It can be seen from Figs 17 and 18 that the specimens strengthened by CFRP strips having smaller spacing had more axial load carrying capacity than that of columns having larger spacing of CFRP strips. The column HS-50-20-T1(3), has higher axial load carrying capacity of $1008 \mathrm{kN}$ compared to column HS-5040-T1(3) which has a load carrying capacity of $989 \mathrm{kN}$ is shown in Fig. 19. The enhancement in load carrying capacity of columns HS-50-20-T2(2) and HS-50-20$\mathrm{T} 3(1)$ is $3.77 \%$ and $6.56 \%$ respectively more than that of columns HS-50-40-T2(1) and HS-50-40-T3(2) 


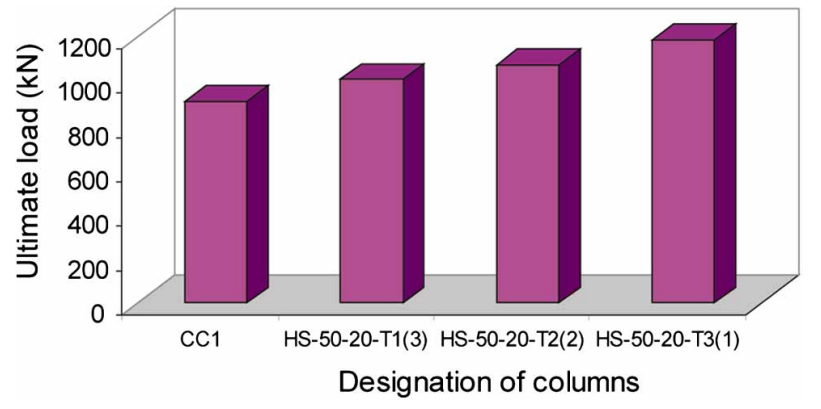

Fig. 17. Ultimate load for columns HS-50-20 - comparison

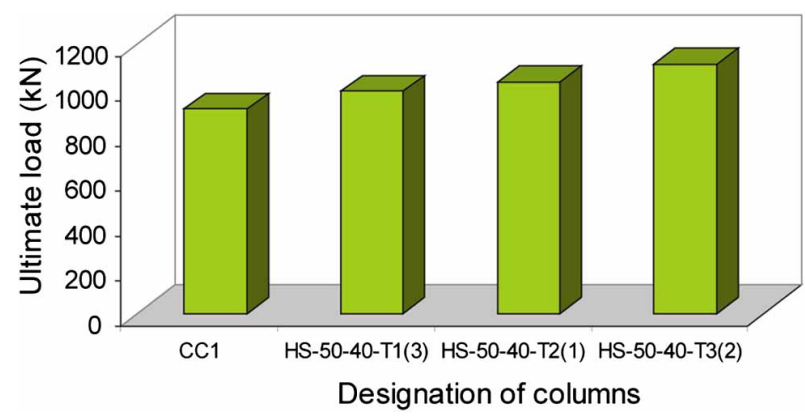

Fig. 18. Ultimate load for columns HS-50-40 - comparison

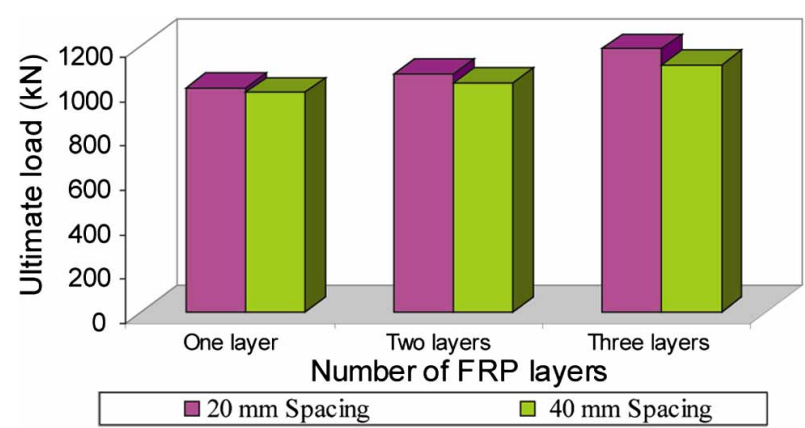

Fig. 19. Ultimate load with respect to number of CFRP layers - comparison

respectively as shown in Fig. 19. The difference in load carrying capacity is due to drop in confining pressure exerted by the CFRP strips when increasing the spacing between the CFRP strips.

Significant enhancement in load carrying capacity was not observed in the case of columns confined by single layer of CFRP strips in both the spacing which is due to insufficient generation of confinement pressure. From the Fig. 19, it can be seen that the axial load carrying capacity of the confined columns increases as the number of CFRP layers increases and also enhancement in axial load carrying capacity was not proportional. Column HS-50-20-T3(1) enhanced their axial load carrying capacity by $17.54 \%$ and $10.55 \%$ more than that of columns HS-50-20-T1(3) and HS-50-20-T2(2) respectively. Similarly, the column HS-50-40-T3(2) which is having $12.44 \%$ and $7.64 \%$ more load carrying capacity than that of columns
HS-50-40-T1(3) and HS-50-40-T2(1), respectively. From the above observations, it can be concluded that external bonding of CFRP strips significantly enhance axial load carrying capacity and delaying the buckling of CFST column and also it is suggested that both the wrapping schemes used in this research work are suitable for strengthening of columns subjected to axial compression.

\subsection{Effect on ductility response}

Ductility is defined as the ability of material to plastically deform without any breaking. Ductility index of the control and CFRP strengthened beams were found as per Tao et al. (2006) and shown in Figs 20 to 22 .

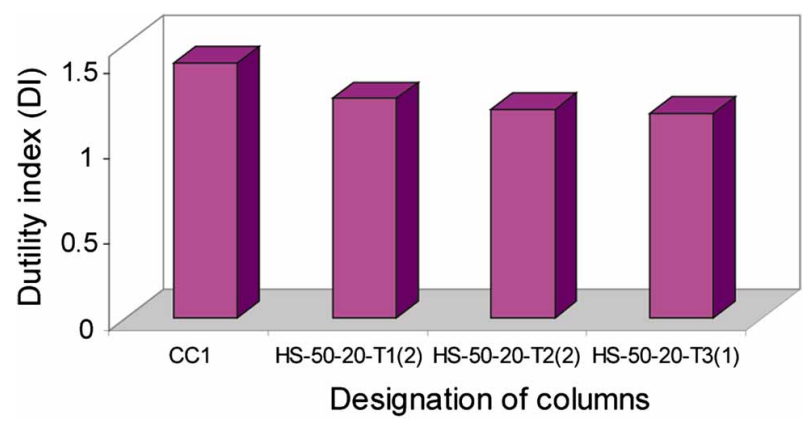

Fig. 20. Ductility Index for columns HS-50-20 comparison

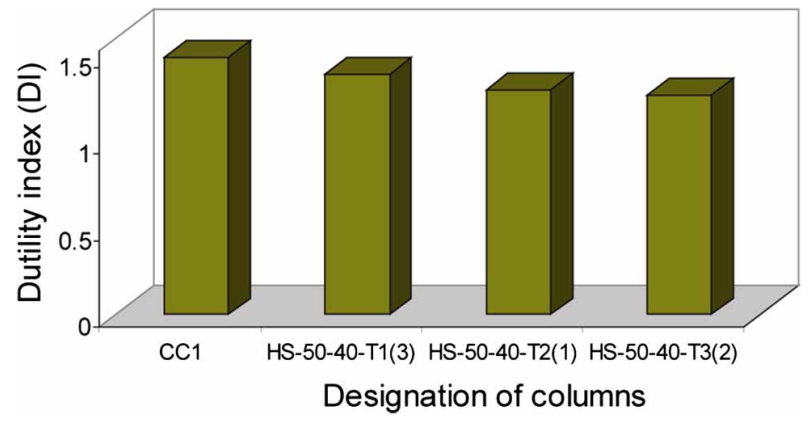

Fig. 21. Ductility Index for columns HS-50-40 comparison

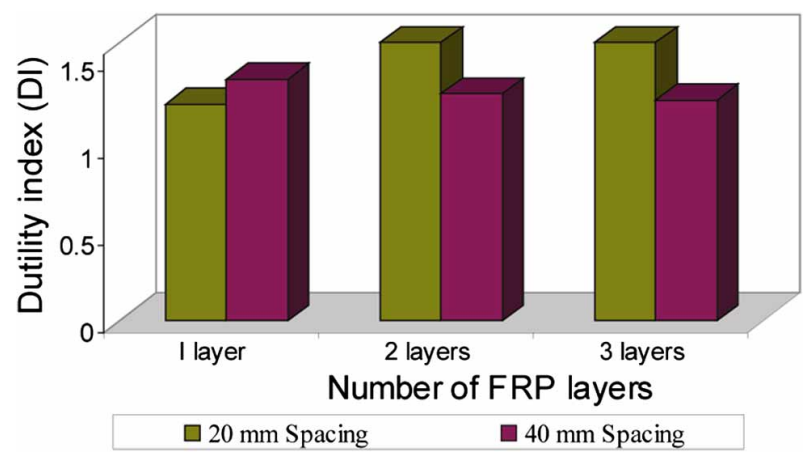

Fig. 22. Ductility Index for all columns - comparison 
It has been found that the control specimen exhibited more ductile nature compared to CFRP strengthened beams and also the ductility of the strengthened specimens decreased when the number of FRP layers increased. This decrease in ductility is due to the sudden rupture of CFRP fabrics. It can be seen from the Fig. 22 that ductility of the confined columns increases as the spacing of the CFRP layers increases. This increase in ductility may due to reduction of CFRP layers.

\section{Conclusions}

Horizontal wrapping style of narrow strip of CFRP fabrics is proposed in this study for improving the confinement pressure of concrete filled steel tubular members externally. From the experimental data obtained, the failure modes, axial stress-stain behaviour, ultimate load carrying capacity and the contribution of FRP fabrics on CFT columns were discussed. And also analytical model was developed for predicting the axial load capacity of CFRP confined CFST columns. Based on the compressive tests on eighteen specimens wrapped with CFRP strips with different spacing, the following conclusions can be made:

- The delamination of fibre due to outward buckling of steel tube was observed on the sides of the CFST members only after the rupture of fibre in the case of specimens with one and two layer of CFRP strips. Therefore, it can be understood that a good composite action exist between the two components were confirmed;

- The control and confined columns exhibited the elastic behavior at initial stage followed by inelastic response when increasing the load further and in addition significant fall in curve was observed at the peak stage due to sudden rupture of CFRP;

- The CFST members confined by CFRP fabrics sustained higher ultimate load and larger axial deformation compared to control column;

- The enhancement in axial deformation and its control of specimens HS-50-20-T1(2), HS-50-20T2(2) and HS-50-20-T3(1) was $12.2 \%, 56.66 \%$ and $89.05 \%$, respectively, but it was $6.2 \%, 42.23 \%$ and $36.24 \%$, respectively, for HS-50-40-T1(3), HS-50-40-T2(1) and HS-50-40-T3(2) more than that of control column, respectively;

- The columns confined with three layers of CFRP tend to have more ability to control axial deformation compared to those columns confined by one and two layers of CFRP, in addition, the enhancement in axial deformation control due to increase in number of layers was not proportional;
- In general, the specimens strengthened by CFRP strips having smaller spacing had more axial load carrying capacity than that of columns having larger spacing of CFRP strips. The enhancement in axial load carrying capacity of columns HS-50-20-T1(3), HS-50-20-T2(2) and HS-50-20-T3(1) was found to be $10.72 \%, 17.80 \%$, and $30.21 \%$ more than that of control column, respectively. In similar manner, the columns HS-50-40-T1(3), HS-50-40-T2(1) and HS-50$40-\mathrm{T} 3(2)$ showed $8.68 \%, 13.51 \%, 22.19 \%$ of more load carrying capacity than the control column, respectively;

- It was also found that the ductility of the strengthened specimens decreased when the number of fibre layers increased and also ductility of the confined columns increases as the spacing of the CFRP layers increases;

- From the above observations, it can be concluded that external bonding of CFRP strips significantly enhance axial load carrying capacity and delaying the buckling of CFST column and also it is suggested that both the wrapping schemes used in this research work are suitable for strengthening of columns subjected to axial compression.

\section{Acknowledgement}

This research work has been carried out through the research funding [Grant No. SR/FT/ET-019/2009] received from SERC-DST, New Delhi, India under Fast Track Project for Young Scientists.

\section{References}

Balazs, G. L.; Borosnyoi, A. 2001. Long-term behavior of FRP, in Proc. of the International Workshop on Composites in Construction: A Reality, American Society of Civil Engineers, VA, 84-91.

Choi, K.-K.; Xiao, Y. 2010. Analytical model of circular CFRP confined concrete-filled steel tubular columns under axial compression, Journal of Composites for Construction ASCE 14(1): 125-133. http://dx.doi.org/ 10.1061/(ASCE)CC.1943-5614.0000056

Hollaway, L. 1993. Polymer composites for civil and structural engineering. Glasgow: Blackie Academic and Professional. 259 p. http://dx.doi.org/10.1007/978-94-011-2136-1

Hollaway, L. 1994. Handbook of polymer composites for engineers. 1st ed. Cambridge: Woodhead Publishing Ltd. 352 p. http://dx.doi.org/10.1533/9781845698607

IS 4923:1997. Indian standard Hollow steel sections for Structural use - Specification.

IS 10262:1987. Recommended Guidelines for Concrete Mix Design.

Jiao, H.; Zhao, X.-L. 2004. CFRP strengthened butt-welded very high strength (VHS) circular steel tubes, ThinWalled Structures 42(7): 963-978. http://dx.doi.org/10.1016/j.tws.2004.03.003 
Lam, L.; Teng, J. G. 2002. Strength models for fiberreinforced plastic-confined concrete, Journal of Structural Engineering ASCE 128(5): 612-623. http://dx. doi.org/10.1061/(ASCE)0733-9445(2002)128:5(612)

Miller, T. C.; Chajes, M. J.; Mertz, D. R.; Hastings, J. N. 2001. Strengthening of a steel bridge girder using CFRP plates, Journal of Bridge Engineering ASCE 6(6): 514-522. http://dx.doi.org/10.1061/(ASCE)1084-0702 (2001)6:6(514)

Photiou, N. K.; Hollaway, L. C.; Chryssanthopoulos, M. K. 2006. Strengthening of an artificially degraded steel beam utilising a carbon/glass composite system, Construction and Building Materials 20(1-2): 11-21. http://dx.doi.org/10.1016/j.conbuildmat.2005.06.043

Peters, S. (Ed.). 1998. Handbook of composites. 2nd ed. London: Chapman \& Hall. 1140 p.

Seica, M. V.; Packer, J. A. 2007. FRP materials for the rehabilitation of tubular steel structures for underwater applications, Composite Structures 80(3): 440-450. http://dx.doi.org/10.1016/j.compstruct.2006.05.029

Sen, R.; Liby, L. 1994. Repair of steel composite bridge sections using CFRP laminates. U.S. Department of Transportation Contract B-7932, Tampa, FL: University of South, Florida.

Tao, Z.; Han, L.-H. 2007. Behaviour of fire-exposed concrete-filled steel tubular beam columns repaired with CFRP wraps, Thin-Walled Structures 45(1): 63-76. http://dx.doi.org/10.1016/j.tws.2006.11.004

Tao, Z.; Han, L.-H.; Zhuang, J.-P. 2006. Cyclic performance of fire-damaged concrete-filled steel tubular beamcolumns repaired with CFRP wraps, Journal of Constructional Steel Research 64(1): 37-50. http://dx.doi.org/10.1016/j.jcsr.2007.02.004

M. C. SUNDARRAJA. Dr, Assistant Professor in School of Civil Engineering at Thiagarajar College of Engineering, Madurai, India. He is a member of Institution of Engineers (India). He contributed much to FRP strengthening in concrete structures through his $\mathrm{PhD}$ research work by publishing papers in International and National Journals and also through his Post-Doctoral Fellowship carried at Queensland University of Technology, Australia under Endeavour Awards in FRP strengthening of high performance steel structures. He extended his research on FRP strengthening of CFST members by receiving research funding projects from UGC and DST, India at a total cost of Rs.21.54 lakhs. And also he is guiding Post Graduate and PhD research students in the field of strengthening of hollow and concrete filled steel tubular structures using advanced FRP composites.

G. GANESH PRABHU. PhD research student in Structural Engineering at Thiagarajar College of Engineering, Madurai, India. He has completed research work on effect of hole on ultimate strength of steel plates using ANSYS in his Post Graduate degree. He is working as a Research Associate in Major Research Project received from UGC, India by Dr M. C. Sundarraja and also carrying his research work on FRP strengthening of CFST members under flexure and compression. He has acquired working kNowledge on ANSYS modelling software. Now he is at the stage of completing his research work and started publishing his work in International Journals and Conferences. 